Preface

\title{
Innovations in Thrombosis and Hemostasis: A Glimpse Towards the Future of Diagnostic Analyzers
}

\author{
Elizabeth M. Van Cott, MD ${ }^{1}$ Kristi J. Smock, MD² \\ ${ }^{1}$ Coagulation Laboratory, Massachusetts General Hospital, Harvard \\ Medical School, Harvard University, Boston, Massachusetts \\ ${ }^{2}$ ARUP Hemostasis/Thrombosis Laboratory, University of Utah School \\ of Medicine, Salt Lake City, Utah \\ ${ }^{3}$ Laboratory of Clinical Chemistry and Hematology, University \\ Hospital of Verona, Verona, Italy
}

Giuseppe Lippi, MD ${ }^{3}$

Semin Thromb Hemost 2019;45:225-227.

For several decades, coagulation analyzers have detected clot formation in one of two ways: optical or mechanical. ${ }^{1}$ Most automated analyzers currently used in hemostasis laboratories are capable of performing other types of testing as well, such as chromogenic, latex agglutination, and even enzymatic immunoassays. ${ }^{1}$ In this special issue of Seminars in Thrombosis and Hemostasis (STH), we particularly wished to explore whether new methods of clot detection, or other novel types of coagulation analyzers, are in development or will soon be ready for prime time for use in routine diagnostics of hemostasis disorders. In reviewing these novel devices, we may also be able to glance into the future to see what new ways of testing in the field of thrombosis and hemostasis may become available. Most of the novel devices we encountered on this journey are small, designed for point-of-care use, in part to maintain lower costs and to use less blood volume. Nevertheless, the new technologies described in this issue of STH could in time be incorporated into larger instruments. Several new developments in larger existing analyzers have also been identified in this issue. ${ }^{1}$ Moreover, several of the novel devices offer possible alternative means to study platelet aggregation, a laboratory test procedure that is currently complex and time-consuming to perform.

Favaloro and Lippi begin this issue by reporting on new advances in mainstream automated coagulation analyzers that are currently already in clinical use. ${ }^{1}$ Six manufacturers were invited to submit information for this report, such as mechanisms employed to reduce interference from hemolysis, icterus, and lipemia (HIL), mechanisms for clot or analyte detection (including optical vs. mechanical clot detection, and chemiluminescence and luminescent oxygen channeling immunoassay technology), and also clot waveform analysis (if available). Several tables are included in this review and provide specific details of manufacturer's information. The authors then take

Address for correspondence Elizabeth M. Van Cott, MD, Coagulation Laboratory, Massachusetts General Hospital, Harvard Medical School, Boston, MA (e-mail: evancott@mgh. harvard.edu).
Issue Theme Innovations in Thrombosis and Hemostasis: A Glimpse Towards the Future of Diagnostic Analyzers; Guest Editors: Elizabeth M. Van Cott, MD, Kristi J. Smock, MD, and Giuseppe Lippi, MD.

the reader on an extended tour, touching upon the various laboratory tests improved/affected by new instrumentation, a journey that coincidentally covers many of the tough issues facing laboratories today. This evaluation examines the role of new instrumentation in advanced testing for von Willebrand disease, platelet aggregation, heparin-induced thrombocytopenia, chromogenic factor assays in the new era of modified extended life factor products, D-dimer (the need for harmonization among different methods), DOAC monitoring, and antiphospholipid antibodies.

T2 magnetic resonance (T2MR) is one new and emerging technology that is able to detect clot formation, as used in a novel device described in this issue of STH by Cuker et al. ${ }^{2}$ T2MR is able to detect clot formation based on partitioning of red blood cells and proteins, which occurs during fibrin formation and platelet-mediated clot contraction. This device can be used to measure clotting times, individual coagulation factors, and platelet function. T2MR also revealed a novel "hypercoagulable" signature that needs further study to determine if it can be used to predict patients at higher risk of thrombosis.

Acoustic waves are alternatively used in another novel, miniaturized point-of-care device capable of using only a small amount of citrated whole blood, measuring the time required for fluorescent microspheres to cease motion due to clot formation, as described by Harder et al. ${ }^{3}$ Overall, $1 \mathrm{~mL}$ of whole blood is initially needed to be collected, but only $<10 \mu \mathrm{L}$ is loaded onto the device. The result provided is a clotting time in seconds. This system may be useful for assessing anticoagulant effects, and the device has been studied in patients receiving different types of anticoagulants such as heparin, argatroban, rivaroxaban, dabigatran, and warfarin.

Infrared spectroscopy is instead used to detect clot formation in the Perosphere Technologies' hand-held point-of-

Copyright $\odot 2019$ by Thieme Medical Publishers, Inc., 333 Seventh Avenue, New York, NY 10001, USA. Tel: +1(212) 584-4662.
DOI https://doi.org/ 10.1055/s-0039-1683844. ISSN 0094-6176. 
care coagulometers, as described by Ansell et al. ${ }^{4}$ This device uses fresh or citrated whole blood $(\sim 10 \mu \mathrm{L})$ with clotting activation initiated by glass contact. The turnaround time is fast, providing a clotting time within 3 to 10 minutes. Preliminary data showed that this device may be useful in assessing coagulation response to any of the direct oral anticoagulants (DOACs) as well as the antithrombin-dependent activated factor X (FXa) inhibiting anticoagulants such as heparin, low molecular weight heparin, and fondaparinux.

Laser speckle rheology (LSR) is employed to detect clot formation using another novel optical hand-held point-ofcare device that performs several coagulation tests including prothrombin time, activated clotting time, clot polymerization rate ( $\alpha$-angle), clot stiffness, fibrinolysis, and platelet function. ${ }^{5}$ As described by Nadkarni, LSR quantifies tissue viscoelasticity from light scattering patterns called laser speckle, using small amounts $(40 \mu \mathrm{L})$ of whole blood and providing test results within 10 minutes.

In yet another novel approach, urine is used as a biological sample instead of blood in a dipstick test to detect the presence or absence of a DOAC. ${ }^{6}$ As detailed by Harenberg et $\mathrm{al}^{6}{ }^{6}$ this approach is potentially less invasive than blood collection, and potentially also eliminates many of the preanalytical issues related to blood collection. ${ }^{7,8} \mathrm{~A}$ dipstick is dipped into a patient's urine sample for 2 to 3 seconds, and after a 10-minute turnaround time, the presence or absence of any of the three most common DOACs (dabigatran, rivaroxaban, and apixaban) in urine can be identified by visually observing specific colors. As an alternative to visual inspection, a hand-held reader can instead be used.

Novel analyzers have also been developed which more specifically assess the role of platelets in human pathologies, including bleeding and thrombotic disorders, cancer, sickle cell disease, stroke, ischemic heart disease, and others. Williams et al describe several analyzers that are already commercially available, and their ability to assess platelet contractile forces. ${ }^{9}$ In development stages, the platelet contraction cytometer is a small device that can assess platelet contractile forces, and preliminary studies suggest that it may identify some patients with a bleeding tendency that cannot otherwise be identified by existing laboratory tests. ${ }^{9}$

Next in this issue, Silva and Grabowski take the reader on a tour of platelet function tests as available in the past and present, and also potentially in the future, including a novel microfluidic device in part aimed to assess patients who have mildly low von Willebrand factor (VWF), distinguishing those who are clinically symptomatic versus asymptomatic. ${ }^{10}$

Emani then reviews the utility of automated digital microfluidics in coagulation testing, with this technology feasibly enabling the performance of up to 12 different tests at once on $<50 \mu \mathrm{L}$ whole blood using small electric fields to manipulate droplets of fluid on a printed circuit board. ${ }^{11}$ The author and his coworkers have used this system to perform genetic testing for FV Leiden and prothrombin G20210A, functional assays for antithrombin, protein C, and FVIII, as well as antigen assays for antithrombin, protein $\mathrm{C}$, protein $\mathrm{S}$, anticardiolipin antibody (immunoglobulin G [IgG], IgM), FVIII, VWF, and homocysteine, as well as for anticoagulant detection by anti-FXa.
Lastly, the special issue concludes with two assessments of some novel analytical approaches in coagulation testing. In the first, the analytical performance of a new coagulation analyzer that utilizes a novel approach of employing liquid and lyophilized reagent cassettes, the Cobas $t 711$ (Roche), is presented. ${ }^{12}$ Resuspension of lyophilized reagent cassettes is automated and more accurate than manual resuspension. Finally, in a Letter to the Editor, this issue ends with a validation of the HIL capabilities of the new Atellica COAG 360 coagulation analyzer. ${ }^{13}$

As Guest Editors to this issue of STH, we realize that there are likely to be many more novel hemostasis devices in development, and that this issue thus represents only a sampling of current and emerging technology in the field. Nevertheless, we hope that you, representing the readership of the journal, will find this issue of interest. We also wish to thank all the authors contributing to this issue of the journal for their original and thoughtful contributions.

Finally, we can also advise that a separate future issue is planned, which will focus on novel hemostasis tests or methodologies rather than on hemostasis analyzers. The in-progress issue is expected to cover many emerging issues related to diagnostic testing in thrombosis and hemostasis, as well as to provide an update on many of the tests used in this field, and would be expected to publish in 2020. As a prelude to this issue, the reader can be directed to several recent reviews and snap-shots of evolving test methodologies in the current literature. ${ }^{14-31}$

\section{Conflict of Interest}

None.

\section{References}

1 Favaloro EJ, Lippi G. Recent advances in mainstream hemostasis diagnostics and coagulation testing. Semin Thromb Hemost 2019; 45(03):228-246

2 Cuker A, Marturano JE, Carinato ME, Lowery TJ, Cines DB. T2 magnetic resonance to monitor hemostasis. Semin Thromb Hemost 2019;45(03):247-252

3 Harder S, Santos SMD, Krozer V, Moll J. Surface acoustic wave-based microfluidic coagulation device for monitoring anticoagulant therapy. Semin Thromb Hemost 2019;45(03):253-258

4 Ansell J, Zappe S, Jiang X, et al. A novel whole blood point-of-care coagulometer to measure the effect of direct oral anticoagulants and heparins. Semin Thromb Hemost 2019;45(03):259-263

5 Nadkarni SK. Comprehensive coagulation profiling at the pointof-care using a novel laser-based approach. Semin Thromb Hemost 2019;45(03):264-274

6 Harenberg J, Schreiner R, Hetjens S, Weiss C. Detecting anti-Ila and anti-Xa direct oral anticoagulant (DOAC) agents in urine using a DOAC Dipstick. Semin Thromb Hemost 2019;45(03):275-284

7 Lippi G, Salvagno GL, Montagnana M, Lima-Oliveira G, Guidi GC, Favaloro EJ. Quality standards for sample collection in coagulation testing. Semin Thromb Hemost 2012;38(06):565-575

8 Lippi G, Favaloro EJ. Preanalytical issues in hemostasis and thrombosis testing. Methods Mol Biol 2017;1646:29-42

9 Williams EK, Oshinowo O, Ravindran A, Lam WA, Myers DR. Feeling the force: measurements of platelet contraction and their diagnostic implications. Semin Thromb Hemost 2019;45(03):285-296

10 Silva RL, Grabowski EF. Flow devices to assess platelet function: a comparison of devices past, present and future. Semin Thromb Hemost 2019;45(03):297-301 
11 Emani SM. Novel coagulation analyzers in development: a glimpse toward the future of microfluidics. Semin Thromb Hemost 2019;45(03):302-307

12 Lippi G, Salvagno GL, Gelati M, Poli G, Giavarina D, Favaloro EJ. Analytical assessment of the new Roche cobas t 711 analyzer fully-automated coagulation analyzer. Semin Thromb Hemost 2019;45(03):308-314

13 Lippi G, Salvagno GL, Poli G, Gelati M, Favaloro EJ. Assessment of plasma sample quality on Siemens Atellica COAG 360 System. Semin Thromb Hemost 2019;45(03):315-318

14 Bonar RA, Lippi G, Favaloro EJ. Overview of hemostasis and thrombosis and contribution of laboratory testing to diagnosis and management of hemostasis and thrombosis disorders. Methods Mol Biol 2017;1646:3-27

15 Favaloro EJ. Diagnosis or exclusion of von Willebrand disease using laboratory testing. Methods Mol Biol 2017;1646:391-402

16 Favaloro EJ. Utility of the von Willebrand factor collagen binding assay in the diagnosis of von Willebrand disease. Am J Hematol 2017;92(01):114-118

17 Favaloro EJ, Mohammed S, Oliver S. The increasing maturity of the von Willebrand factor collagen binding in von Willebrand disease diagnosis. Haemophilia 2018;24(01):20-23

18 Patzke J, Favaloro EJ. Laboratory testing for von Willebrand factor activity by glycoprotein Ib binding assays (VWF:GPIb). Methods Mol Biol 2017;1646:453-460

19 Oliver S, Lau KKE, Chapman K, Favaloro EJ. Laboratory testing for von Willebrand factor multimers. Methods Mol Biol 2017; 1646:495-511

20 Higgins RA, Goodwin AJ. Automated assays for von Willebrand factor activity. Am J Hematol 2018. Doi: 10.1002/ajh.25393

21 Favaloro EJ, Bonar R, Hollestelle MJ, et al. Differential sensitivity of von Willebrand factor activity assays to reduced VWF molecular weight forms: a large international cross-laboratory study. Thromb Res 2018;166:96-105

22 Favaloro EJ, McCaughan G, Mohammed S, et al. HIT or miss? A comprehensive contemporary investigation of laboratory tests for heparin induced thrombocytopenia. Pathology 2018;50(04): 426-436

23 Favaloro EJ. Laboratory tests for identification or exclusion of heparin induced thrombocytopenia: HIT or miss? Am J Hematol 2018;93(02):308-314

24 Mitta A, Curtis BR, Reese JA, George JN. Drug-induced thrombocytopenia: 2019 update of clinical and laboratory data. Am J Hematol 2019;94(03):E76-E78

25 Rodeghiero F. A hit to current "hit" wisdom: a century later, it's time for a change. Am J Hematol 2017;92(08):727-729

26 Favaloro EJ, McCaughan G, Pasalic L. Clinical and laboratory diagnosis of heparin induced thrombocytopenia: an update. Pathology 2017;49(04):346-355

27 Favaloro EJ, Gosselin R, Olson J, Jennings I, Lippi G. Recent initiatives in harmonization of hemostasis practice. Clin Chem Lab Med 2018;56(10):1608-1619

28 Ayanambakkam A, Kremer Hovinga JA, Vesely SK, George JN. Diagnosis of thrombotic thrombocytopenic purpura among patients with ADAMTS13 Activity 10\%-20. Am J Hematol 2017; 92(11):E644-E646

29 Labarque V, Perinparajah V, Bouskill V, et al. Utility of factor VIII and factor VIII to von Willebrand factor ratio in identifying 277 unselected carriers of hemophilia A. Am J Hematol 2017;92(06):E94-E96

30 Saleem R, Reese JA, George JN. Drug-induced thrombotic microangiopathy: an updated systematic review, 2014-2018. Am J Hematol 2018;93(09):E241-E243

31 Favaloro EJ. Clinical utility of closure times using the platelet function analyzer-100/200. Am J Hematol 2017;92(04):398-404 